\title{
ROLAMENTOS AUTOCOMPENSADORES DE ROLOS VEDADOS APRESENTAM EXCELENTES RESULTADOS EM ROLOS DE CORREIAS TRANSPORTADORAS EM MINERAÇÃO DE COBRE NO PERU *
}

Roberto Martinez ${ }^{1}$

Rogério Martelli

\section{Resumo}

Rolamentos autocompensadores de rolos são a normalmente aplicados em caixas de mancal de Correias Transportadoras nas industrias de mineração. Um dos problemas enfrentados pelos usuários são as repetitivas falhas de rolamentos aplicados nestas posições. Na SKF descobriu-se que os rolamentos autocompensadores de rolos vedados são a melhor aplicação para resolver os problemas típicos encontrados nestes equipamentos. A solução fornecida, nestes casos, é o que a SKF chama de Tríplice Barreira de Proteção, que tem como objetivo combater a principal causa de falhas que é a contaminação por partículas minerais e na presença de umidade. Em uma mina de cobre do Peru esta solução foi implementada e totalmente padronizada para todas as correias transportadoras e os resultados alcançados superaram as expectativas.

Palavras-chave: Rolamentos; Vedações; Vida; Contaminação

\section{SEALED SPHERICAL ROLLER BEARINGS SHOWS EXCELLENT RESULTS WHEN APPLIED IN CONVEYORS}

\section{Abstract}

The spherical roller bearings are usually applied in the housings of the Conveyors at mining industries. One of the problems found at the customers are the constant failures of this bearings. In the SKF discovered that the spherical roller bearings are the best of solution to solve typical problems found in this type of machine. The solution supplied, in these cases, is called by SKF how Triple barrier solution that has how main objective to avoid the principal cause of failure that is contamination by mineral particles and humidity. In a cooper mine from Peru this solution was implemented and standarized to all conveyors and the results achieved exceeded the expectations.

Keywords: Bearings; Seals; Life; Contamination

1 Engenharia Mecânica - CIP - Colegio de Ingenieros del Peru, Engenheiro Mecânico, Engenheiro de Aplicação Senior, Engenharia de Aplicação, SKF do Peru, San Isidro, Peru.

2 Engenharia Mecânica - UMC, Engenheiro Mecânico, Engenheiro de Aplicação PL, Engenharia de Aplicação, SKF do Brasil, Cajamar, SP, Brasil. 


\section{INTRODUÇÃO}

Os Transportadores de Correia sofrem frequentes paradas não planejadas devido as falhas dos rolamentos aplicados nos Tambores. Neste cliente uma falha não planejada dos rolamentos, ocasionando a parada do Transportador, pode gerar perdas na ordem de US\$100.000,00 por hora.

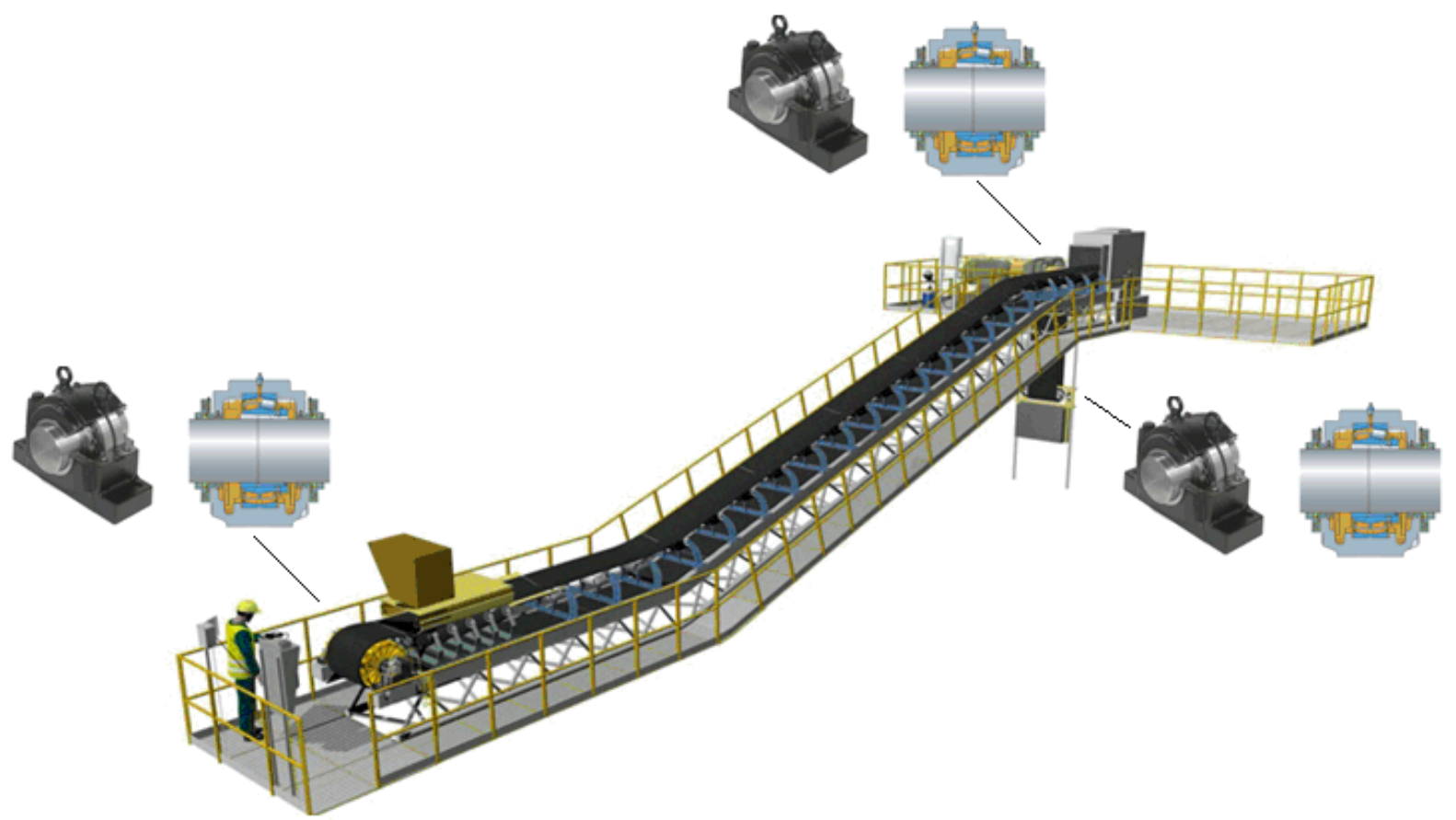

Figura 1. Detalhe do Mancal aplicado no Transportador de Correia.

A configuração dos apoios dos tambores das Correias Transportadoras indicam rolamentos autocompensadores de rolos montados em Caixas de Mancal bipartidas. Normalmente, os rolamentos escolhidos para estas aplicações são da série 230 e 231. Estas satisfazem os requisitos de projetos, porém as vedações aplicadas as caixas de mancal, que desempenham um papel importante contra o ingresso de contaminantes não são suficientes para barrarem as partículas minerais e água existentes no ambiente.

As falhas analisadas comprovam que em sua maioria, as mesmas ocorrem em função da contaminação dos rolamentos.

\section{Descrição do Problema}

Uma companhia de mineração de cobre do sul do Peru em 2012, reportou 40 falhas prematuras nos rolamentos, que significa um tempo médio entre falhas (MTBF) de seis meses. Para todas as falhas realizou-se análises de falhas e na maioria dos casos a causa foi a contaminação severa (ingresso de umidade e partículas finas) como causa principal. 

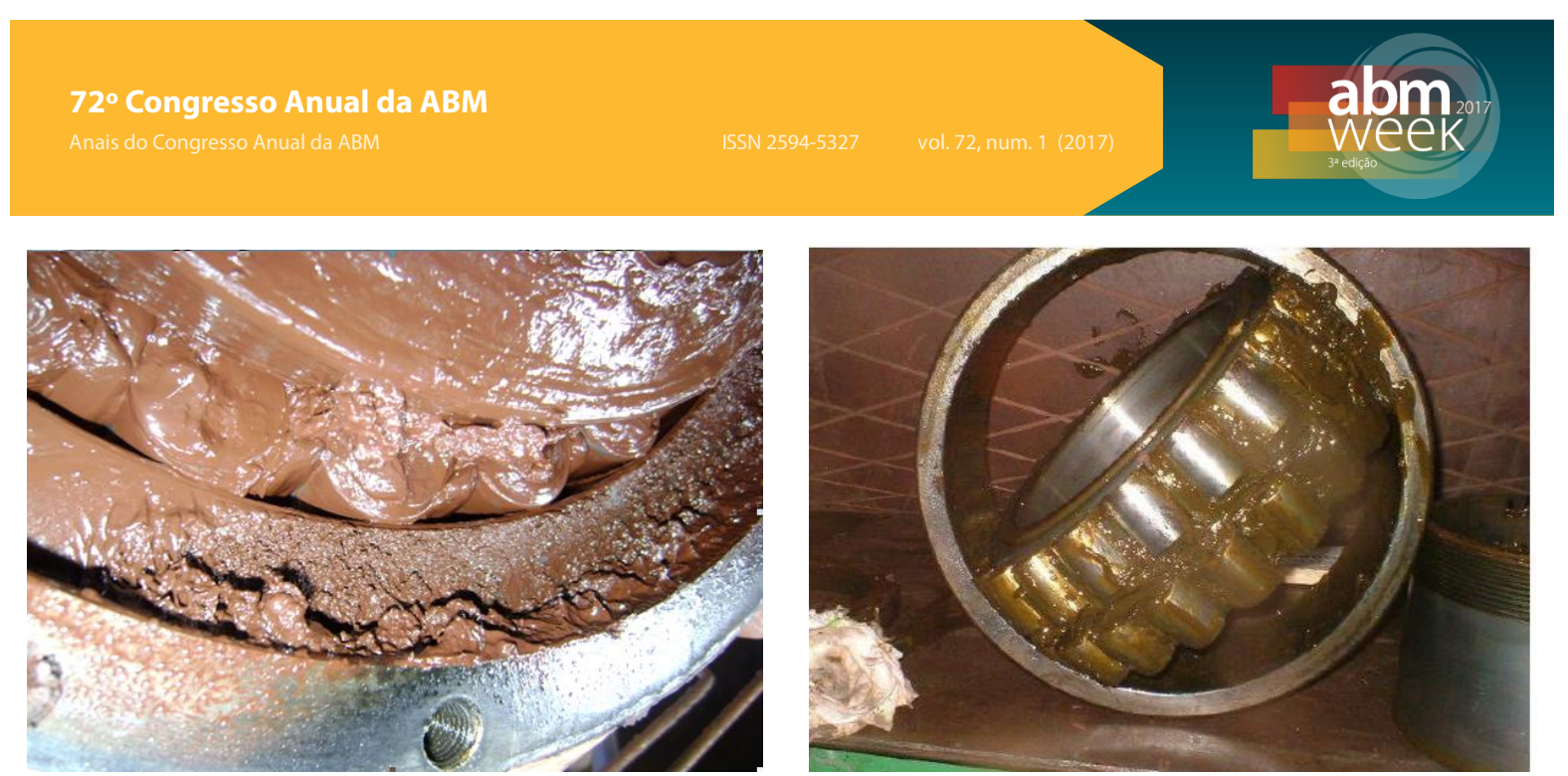

Figuras 2 e 3 - Característica típica encontrada na abertura da caixa de mancal do transportador.

Pôde-se observar os seguintes pontos para descrever o problema:

- As Correias Transportadoras da planta sofreram paradas não programadas devido a falhas nos rolamentos;

- Os projetos originais dos equipamentos forneciam originalmente rolamentos abertos de diversas marcas;

- Perdas de produção devido a paradas não planejadas não ordem de US\$ $50.000,00$ por hora;

- No primeiro ano de operação da planta efetuaram diversas trocas de tambores dos transportadores por falhas de rolamentos, sendo $70 \%$ dos casos devido a contaminação.

Diante dessa situação, relacionada a frequentes paradas não planejadas e com consequente perdas de produção e elevado consumo de rolamentos e acessórios, os usuários solicitaram ajuda da SKF do Peru para buscar uma solução que solucionasse este problema.

\section{Identificando as causas do problema}

Tomemos um dos casos comuns de causa prematura que se apresentam nos rolamentos de apoio dos tambores dos Transportadores

Caso: os rolamentos de um tambor foram instalados em junho de 2012 e no final do mês de outubro do mesmo ano o departamento de manutenção preditiva detectou sinais de aumento dos níveis de vibração, principalmente na pista do anel externo do rolamento.

Análise de falha do rolamento (RFA): Se decide intervir na máquina após aproximadamente 3200 horas de operação e se observa o mesmo padrão de falha em ambos os rolamentos. 

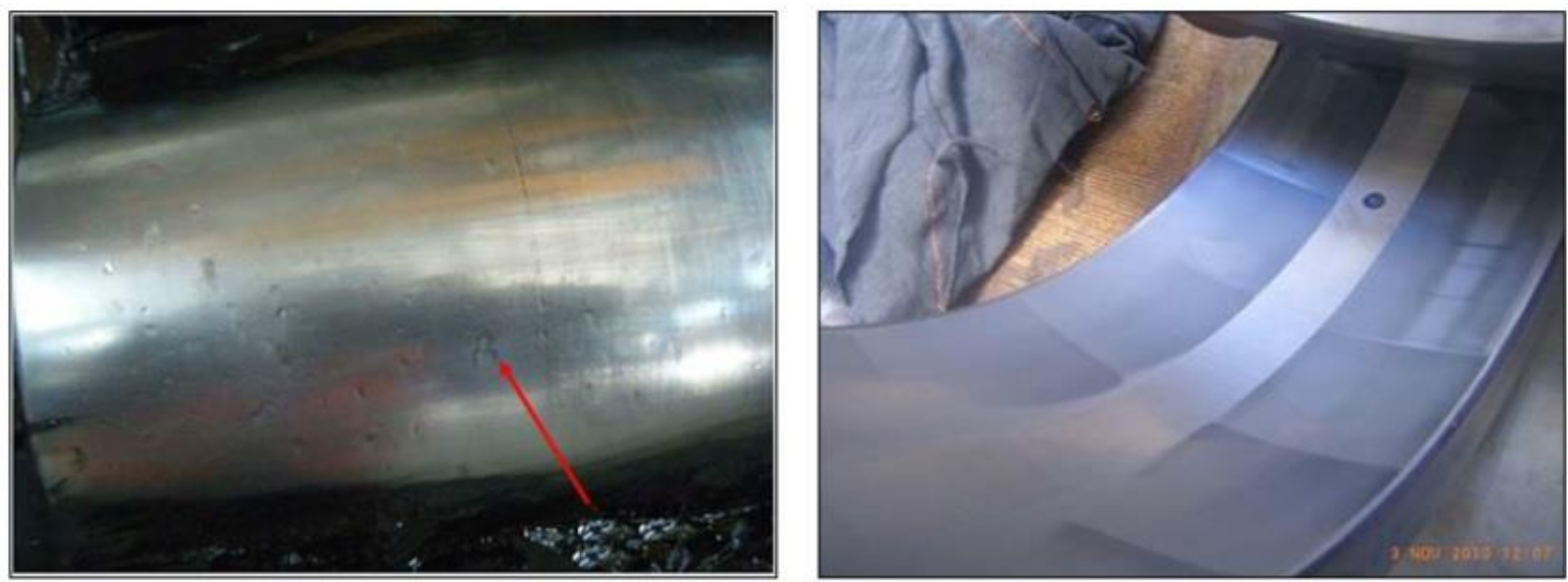

Figuras 4 e 5 - Avaliação dos componentes dos rolamentos.

Causas: o resultado da RFA nos mostra que as causas que conduziram as falhas foram:

- O ingresso de contaminantes no rolamento que origina um modo de falha que se conhece como "deformação plástica - identificado por contaminação" [4 e $5]$;

- Uma combinação de efeitos de: desgaste abrasivo [4 e 5] (presença de contaminantes finos) + baixo sangramento do óleo base da graxa devido a baixa temperatura + vibrações de baixa frequência do conjunto.

Recomendações:

- Melhorar o sistema de vedação dos rolamentos, seguindo um conceito de tripla barreira de vedação;

- Utilizar rolamentos vedados com uma graxa de melhor rendimento sob baixas temperaturas.

\section{Solução SKF Tríplice Barreira}

Para as condições mais agressivas por contaminação a SKF recomenda a solução de Tríplice Barreira, a qual consiste utilizar uma caixa de mancal com vedação de anel labirinto (ou taconite) e um rolamento autocompensador de rolos vedados. 


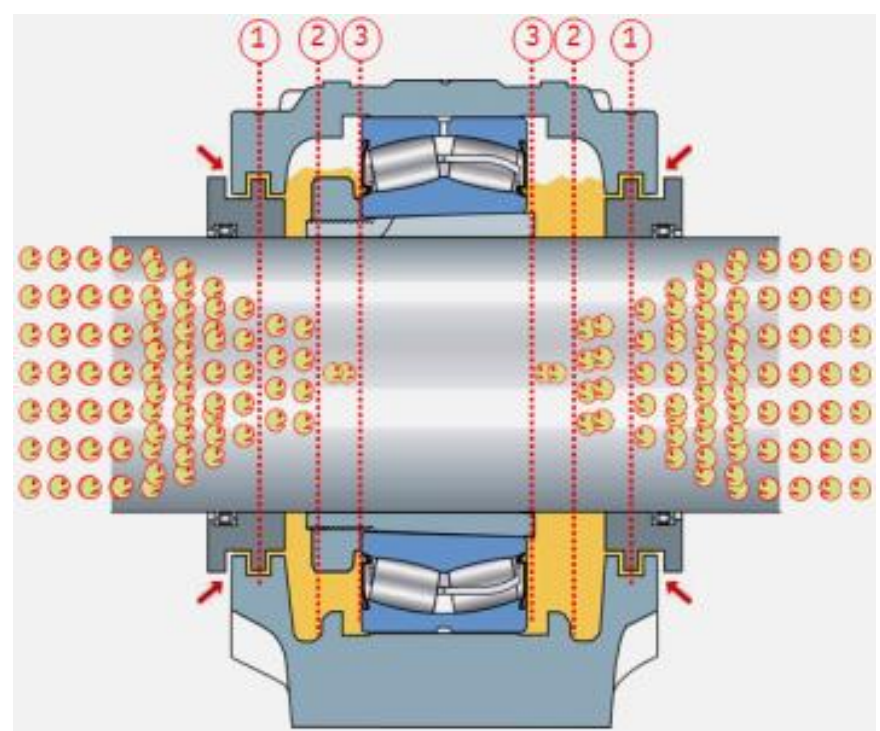

Figura 6 - Conceito "SKF Tríplice Barreira".

O sistema de Tríplice Barreira que forma [6]

1 - Vedação labirinto (ou taconite): são a primeira barreira para evitar a entrada de contaminantes;

2 - Graxa dentro da caixa de mancal: é a segunda barreira que a contaminação encontra antes de chegar ao rolamento;

3 - Rolamentos autocompensadores de rolos vedados: o rolamento é fornecido com vedações em ambos os lados e lubrificados de fábrica.

Neste caso é importante a seleção da graxa correta que leva o rolamento vedado. A graxa adotada foi a SKF LGWM2 que possui bom rendimento em baixas temperaturas. É a mais adequada para as condições de operação de rolamentos nesta aplicação da Mineradora Peruana.
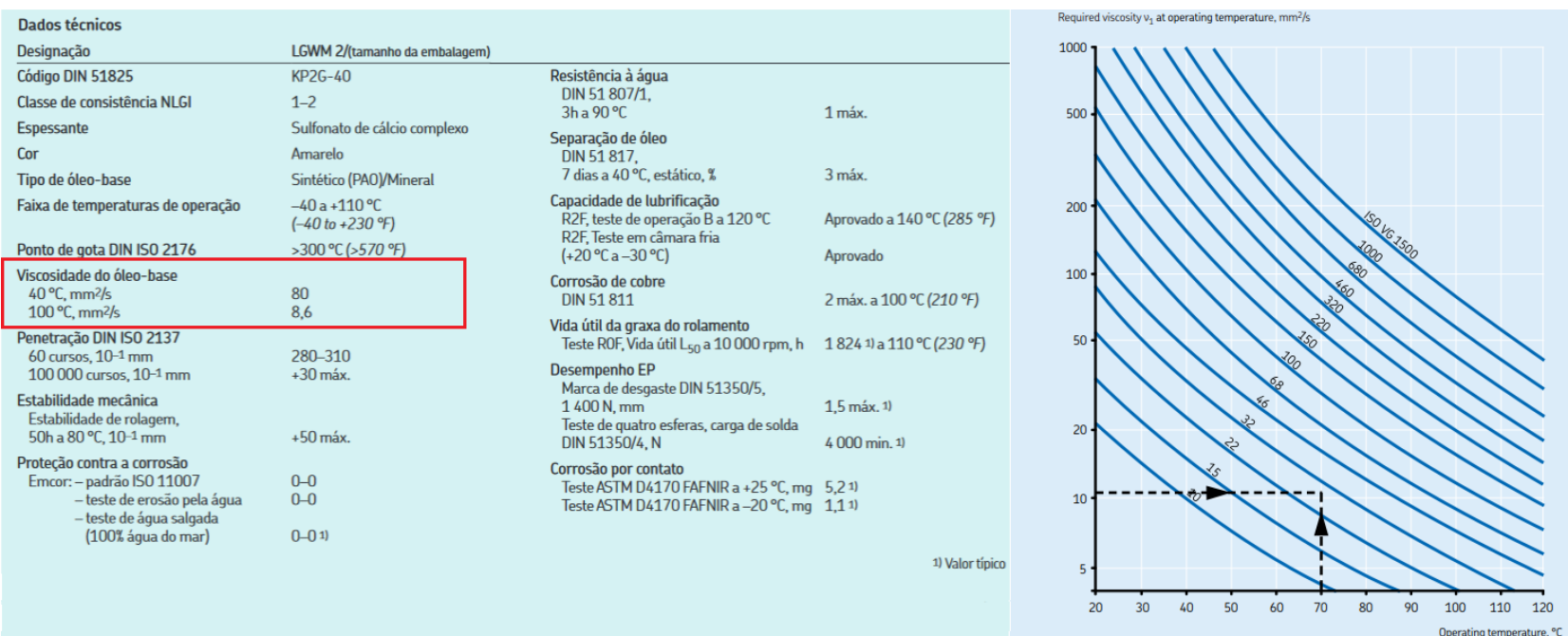

Figura 7 - Características apropriadas para o lubrificante. 


\section{Rolamentos autocompensadores de rolos - Geração Explorer}

Os rolamentos autocompensadores de rolos tem duas carreiras de rolos esféricos que transmitem a carga através de pistas esféricas nos anéis internos e externos. São autoalinháveis, portanto pouco sensíveis a desalinhamentos angulares do eixo com relação ao alojamento e a flexão. São os ideais para suportar altas cargas radiais e axiais. É por essa razão que estes rolamentos são utilizados para condições de operação de apoio em Tambores de Correias Transportadoras. As séries 230 e 231 são as preferidas pelos fabricantes de Transportadores.
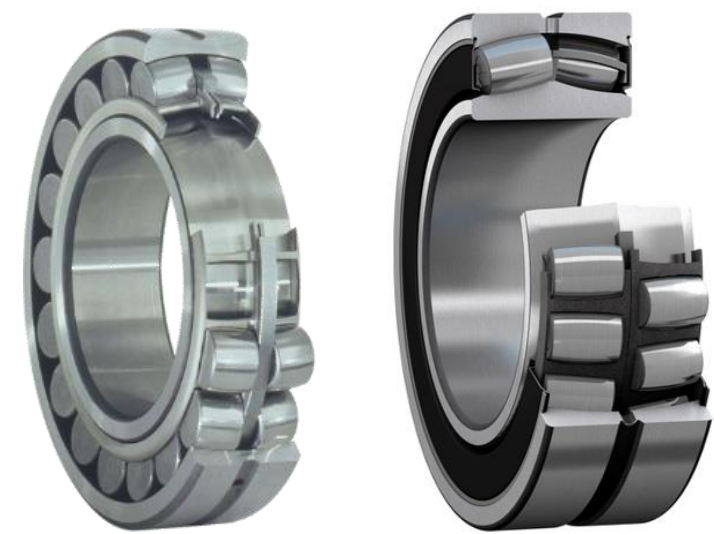

Figuras 8 e 9 - Rolamento autocompensador de rolos aberto e vedado.

Os materiais possuem papel importante na vida em serviço dos rolamentos. Outro fator é o seu comportamento em ambientes contaminados. O projeto em questão visou a utilização destes dois fatores que foi a tecnologia Explorer, que utiliza um aço com teor de oxigênio bastante reduzido que proporciona um aumento da dureza superficial reduzindo desgaste das pistas e, também, a utilização da vedação no rolamento. A finalidade é aumentar o fator $\mathbf{\eta}_{\mathbf{c}}$, que representa 0 nível de contaminação ao qual o rolamento está submetido. $O$ ábaco da figura 10 indica a relação entre desgaste em materiais diferentes e o ábaco da figura 11 indica os fatores que elevam a vida em serviço, em função do material aplicado e do $\boldsymbol{\eta}_{\mathbf{c}}$.

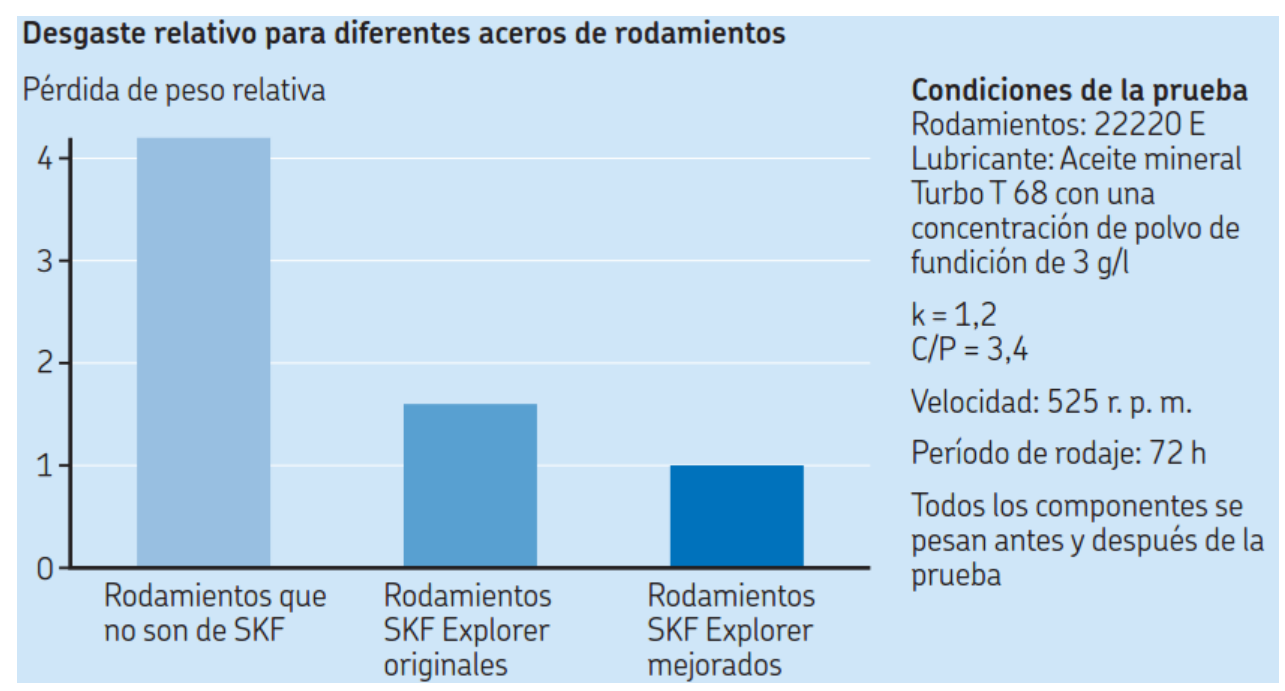

Figura 10 - Testes de resistência ao desgaste em rolamentos. 
- Aumento da vida em serviço dos rolamentos em ambientes contaminados, exemplificado na Figura 11 (fator de contaminação $\mathbf{\eta}_{\mathbf{c}}=0,1-0,4$ para rolamentos abertos, linha vermelha; $\mathbf{\eta}_{\mathbf{c}}=0,6-0,9$ para rolamentos vedados, linha verde);

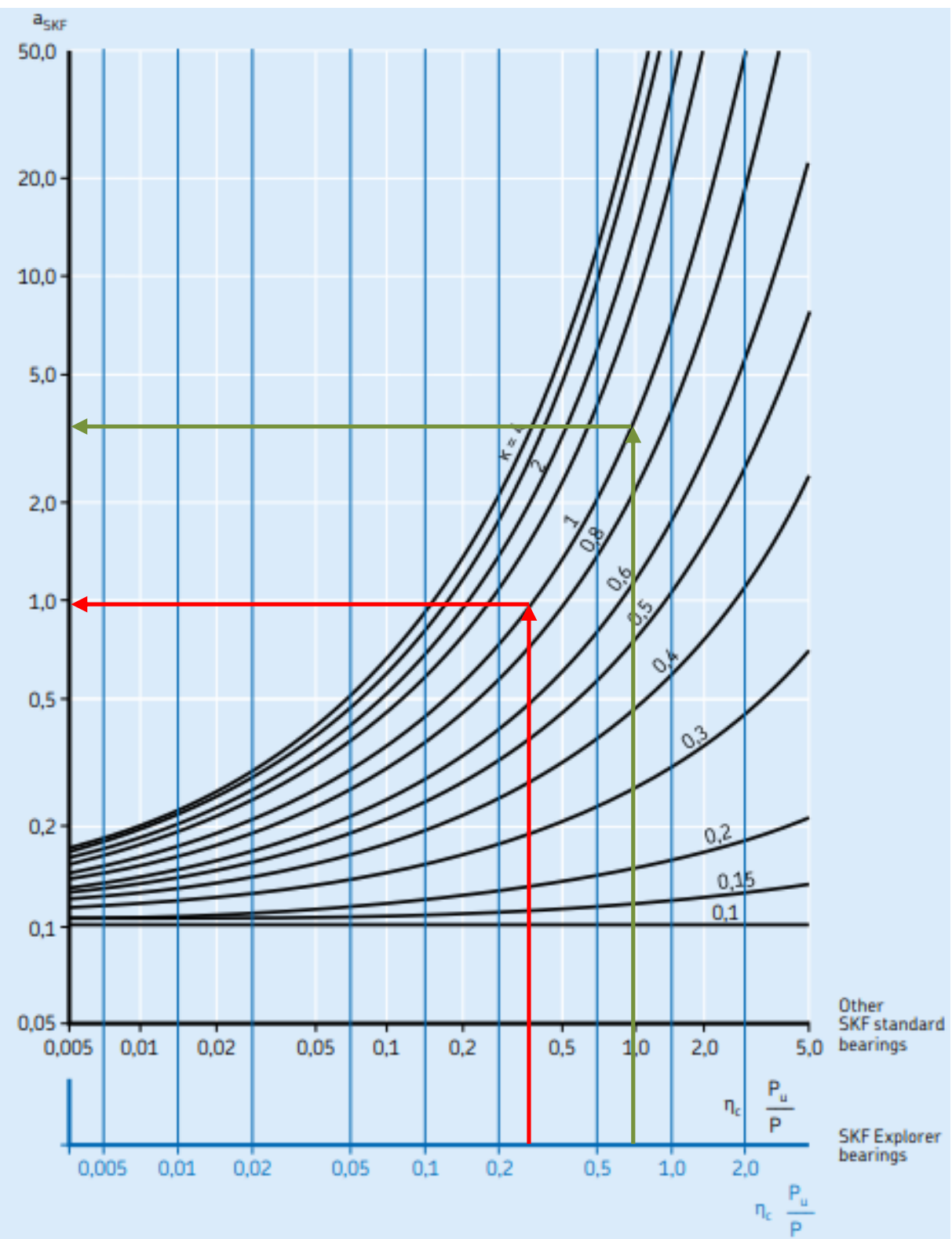

Figura 11. Ábaco do fator askf para rolamentos de rolos, considerado $K=1$ e $P u / P=1$.

- Aumento da confiabilidade do equipamento;

- Redução dos custos de manutenção;

- Redução do consumo de lubrificante;

- Redução de impactos ambientais. 
É importante mencionar que os rolamentos foram instalados em caixas de mancal SKF série SNLD [10] para estes rolamentos, para dar maior segurança as condições de cargas exigidas. Estas caixas de mancal de ferro fundido nodular, que é 1.8 vezes mais resistente as cargas em todas as direções em comparação com o ferro fundido cinzento que é um material standard.

\section{O PAPEL DA GRAXA NOS ROLAMENTOS AUTOCOMPENSADORES DE ROLOS VEDADOS}

Para que o rolamento lubrificado com graxa desenvolva uma lubrificação adequada é necessário que o espessante possa sangrar seu óleo base sob baixas condições de temperatura de operação. Na SKF se aplica o conceito do farol para as graxas que lubrificam os rolamentos.

O conceito do farol contempla que a graxa sangre corretamente seu óleo base num intervalo de temperatura da zona verde mostrada no gráfico da figura 9.

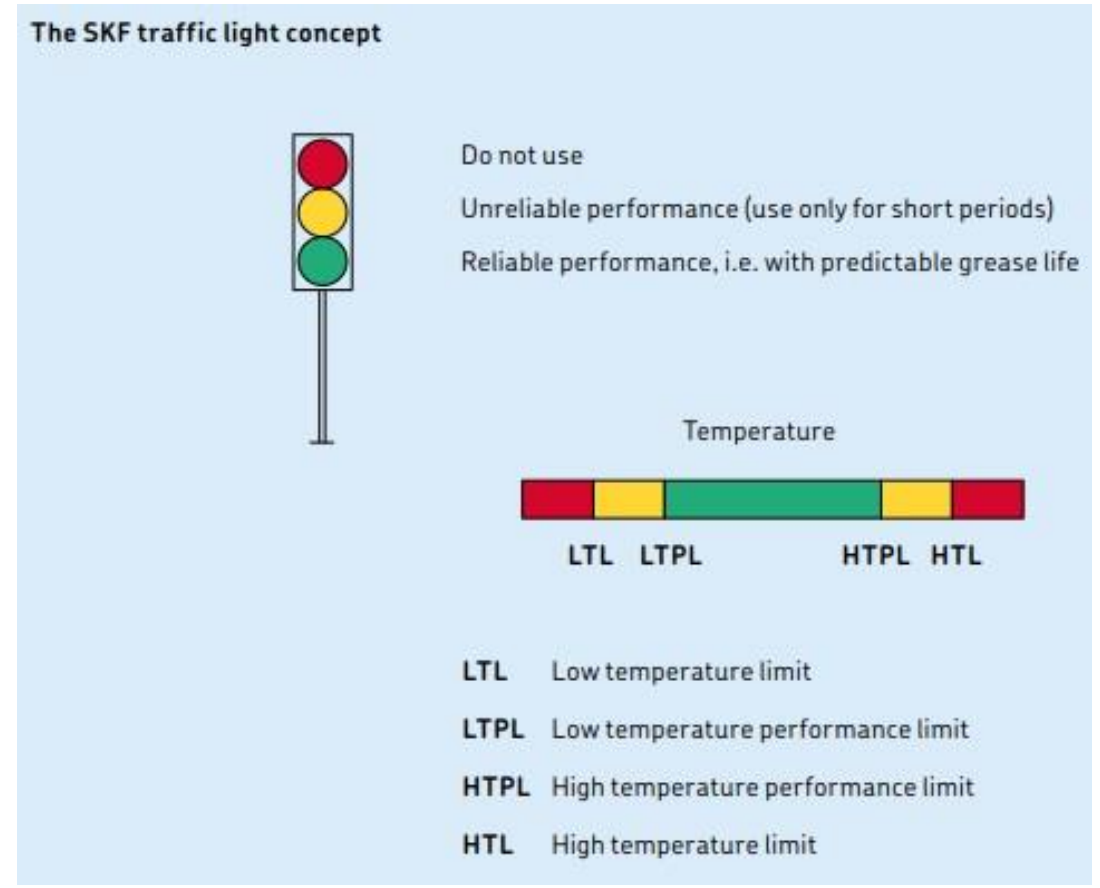

Figura 12 - Conceito do Farol.

Na zona amarela de baixa temperatura se dá um sangramento insuficiente de óleo e um aumento da resistência interna. Por outro lado, na zona amarela de alta temperatura se dá um excesso de sangramento de óleo, amolecimento e oxidação, pelo que se considera que o rendimento da graxa é limitado. Portanto é permitido somente para pequenos períodos de tempo. A graxa não deve trabalhar na zona vermelha.

Para definir os limites mostrados no gráfico da figura 9 temos:

- LTL que é a temperatura de início de operação da graxa; 
- LTPL que é a temperatura a partir da qual se dá a lubrificação adequada no rolamento;

- HTPL que é a máxima temperatura da graxa para um bom rendimento;

- HTL que é o ponto de gota da graxa.

Se conclui que a graxa deve trabalhar em um range de temperatura entre LTPL e HTPL para manter uma lubrificação satisfatória. Nas especificações técnicas das graxas todos os fabricantes indicam somente o LTL como valor inferior e o HTPL como valor superior para o intervalo de temperatura das graxas. Isto não é aplicado a lubrificação de rolamentos em que o bom rendimento se dá à partir do LTPL [9].

A graxa utilizada nos rolamentos autocompensadores de rolos vedados é a SKF LGWM2, que apresenta seu intervalo verde LTPL - HTPL na zona de temperatura de operação que são típicas das regiões das mineradoras do Peru.

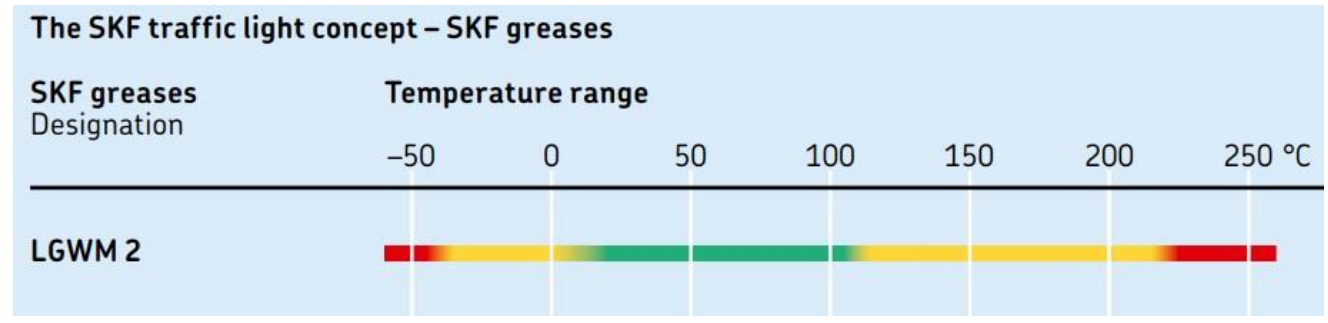

Figura 13 - dados da graxa SKF LGWM 2.

A graxa SKF LGWM 2 sangra corretamente seu óleo base à partir de $10^{\circ} \mathrm{C}$ de temperatura de operação, o que nos permite assegurar as baixas temperaturas típicas que se dão nos tambores das correias transportadoras ( $20^{\circ} \mathrm{C}-50^{\circ} \mathrm{C}$ ), a lubrificação sempre será adequada.

As graxas convencionais utilizadas nos rolamentos abertos dos tambores para as correias transportadoras, geralmente são graxas com espessante de lítio, complexo de lítio, e as que possuem espessante de poliuréia, etc. A maioria delas possuem um LTPL > 40ㄷ - 45ㄷ como início da zona verde. As faixas apresentadas partem de uma combinação de efeitos de desgaste por abrasão (presença de contaminantes finos) + um escasso sangramento de óleo base devido a baixa temperatura de operação $\left(<50^{\circ} \mathrm{C}\right)$ + as vibrações de baixa frequência do conjunto, dando como resultado um particular modo de falha que se caracteriza por deixar superfícies onduladas nas pistas dos rolamentos [15].

Um ganho importante observado se deu em função da relubrificação. Com o princípio da tríplice barreira menores intervalos e quantidades de lubrificantes são necessários. Em alguns casos, quando as rotações são mais baixas, se tornam livres de manutenção, ou seja, não necessitam relubrificação, podendo alcançar a vida da graxa até 30.000 horas. 

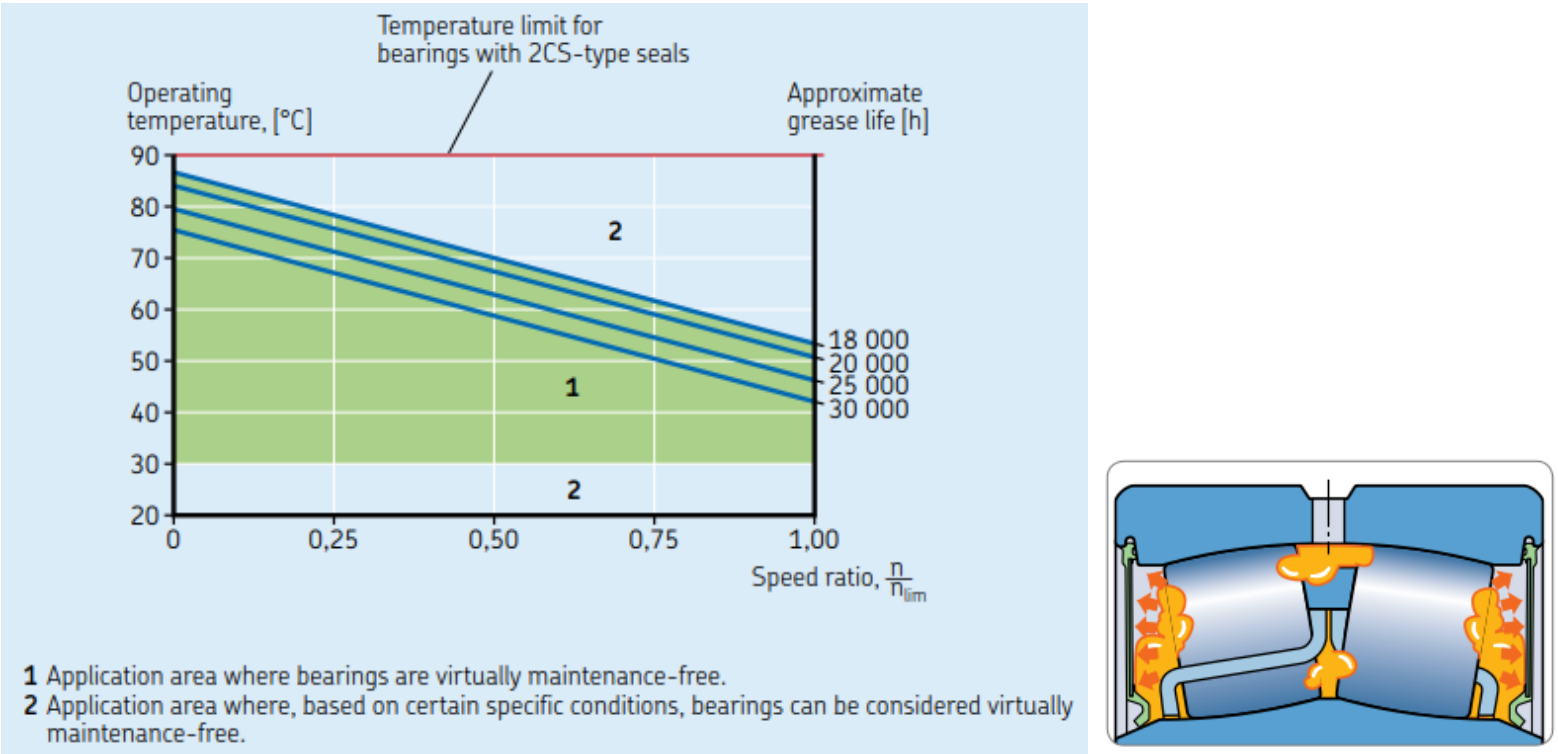

Figura 14 - Ábaco de vida da graxa para rolamentos autocompensadores de rolos vedados.

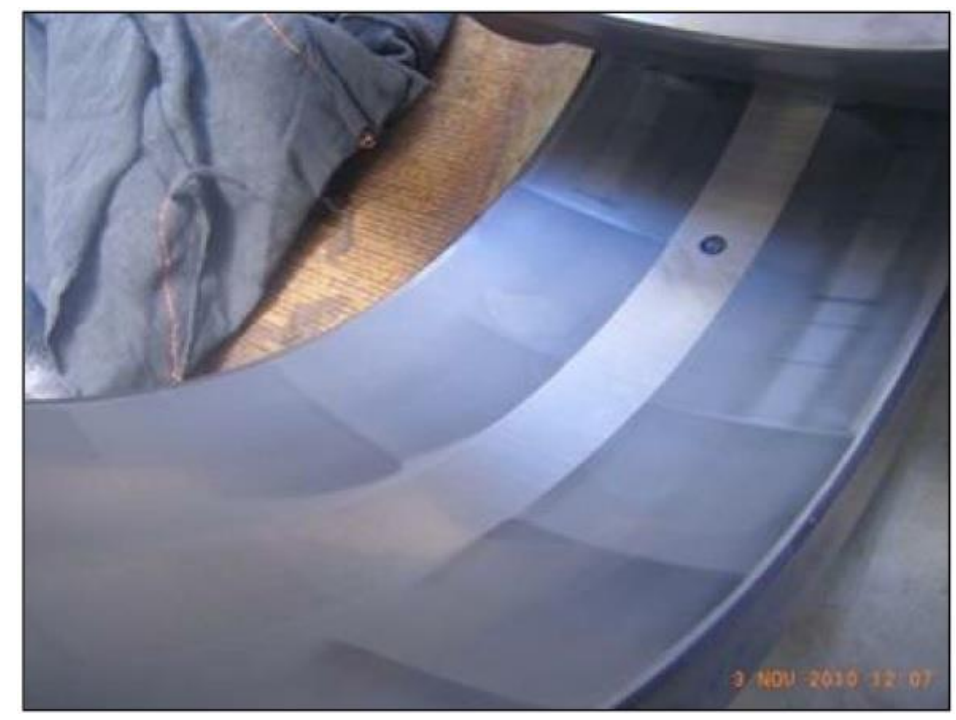

Figura 15 - Dano observado na pista do anel externo do rolamento.

\section{Vedações labirintos ou taconites como primeira barreira}

As caixas de mancal utilizadas para montagem do rolamentos vedados correspondem a série SNLD e com eles teremos várias opções de vedação a seguir. Entre elas, as vedações labirinto e taconite são as preferidas para esta aplicação. Nesta mineradora tem-se utilizado as vedações taconite, que são aplicados para níveis de contaminação extrema [16]. 

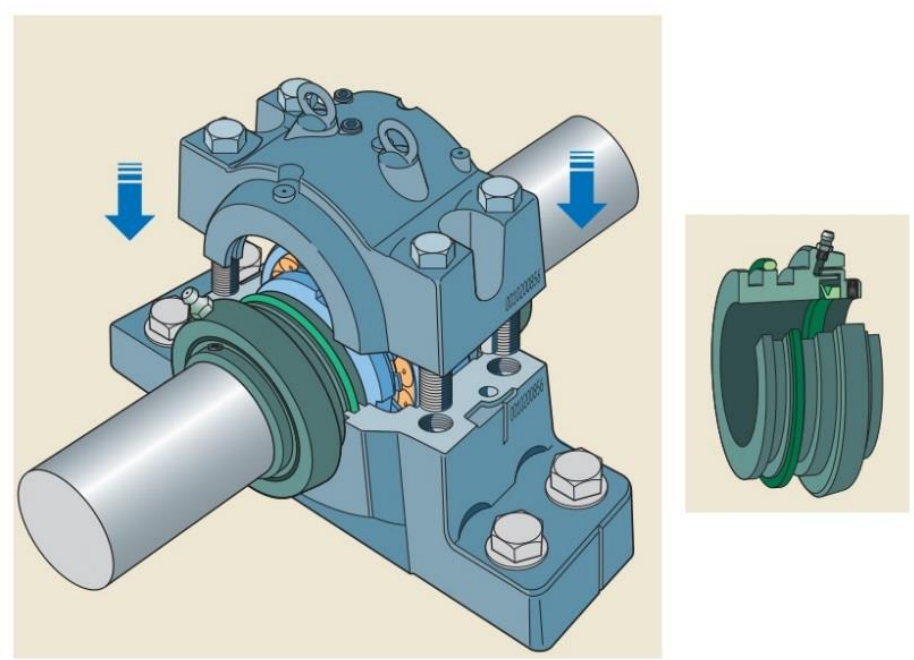

Figura 16 - Exemplo de sistema com caixa de mancal e vedação taconite.

O taconite TNF está baseado em um preenchimento labiríntico radial de três peças que se encaixa na ranhura da caixa de mancal SNLD.

\section{Montagem dos Rolamentos}

Outro fator importante para o sucesso das aplicações é a técnica utilizada na montagem dos rolamentos. Por se tratarem de rolamentos vedados, os mesmos não possibilitam a medição da folga interna radial durante a montagem pelo método tradicional que ocorre através dos calibradores de lâmina. Neste caso, utilizou-se o método do deslocamento axial denominado Drive Up. Este método consiste na redução da folga interna radial do rolamento através aplicação de uma pressão através da bomba hidráulica e deslocamento axial pré-estabelecidos [17].

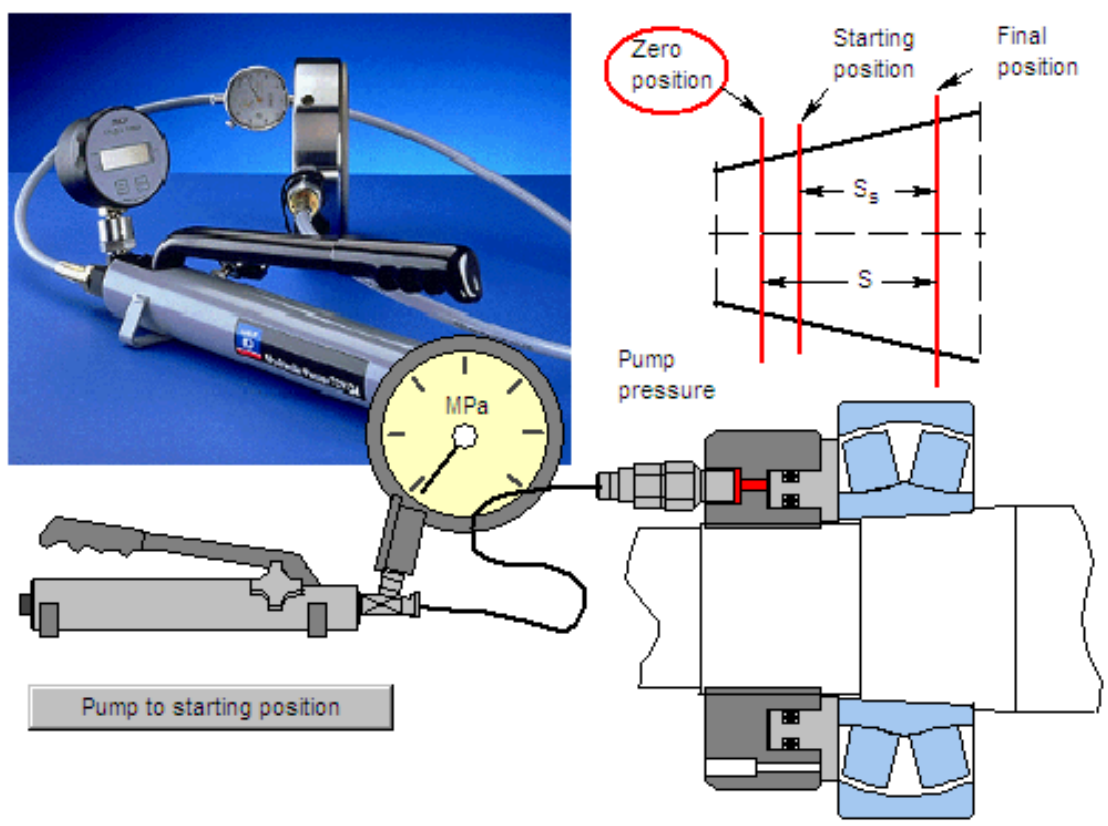

Figura 17 - Método Drive Up aplicado na montagem de rolamentos. 


\section{Conclusões}

Os rolamentos autocompensadores de rolos vedados aplicados ao conceito SKF Tríplice Barreira utilizados nos tambores de correias transportadoras tem superado as expectativas do cliente. Os rolamentos tem sido substituídos por razões preventivas na manutenção onde se tem trocado os revestimentos dos tambores que se realizam a cada 2 ou 3 anos, o que significa um aumento da vida em serviço de 4 a 6 vezes.

A solução tem sido tão efetiva que esta companhia no Peru adotou como stardard a solução tríplice barreira da SKF. Os rolamentos SKF 230xx-2CS5K/GLE e/ou 231xx2CS5K/GLE, onde o sufixo GLE indica que o rolamento vem preenchido com a graxa SKF LGWM 2 [7].

Em destaque cita-se os rolamentos SKF 23284-2CS5K/GLE (dimensões: 420x760x272mm) montados nas caixas de mancal SKF SNLD 3284TS, de grande tamanho, aplicados em 4 das 40 posições citadas.

\section{Referências}

[1] ISO 15243, First edition 2004-02-15, Rolling bearings - Damage and failures Terms, characteristics and causes.

[2] Sealed SKF Explorer spherical roller bearing PUB BU/P2 15501 EN February 2016, pp. 7.

[3] EVOLUTION, Business and technology magazine from SKF, \#2 2012, pp2729.

[4] SKF General Catalogue: "Rolling bearings" PUB BU/P1 10000 EN, October 2012, pp. 244-249.

[5] LGWM 2 - Grasa para grandes cargas y amplio rango de temperaturas, PUB MP/P8 12056 ES, Enero 2014.

[6] Sealed SKF Explorer spherical roller bearings, PUB BU/P2 10704/I, April 2013, pp 7.

[7] SNL 30, 31 and 32 plummer block housing, PUB BU/P1 06101/1 EN, March 2010. 